\title{
The Preparation of Non-aqueous Supercapacitors with Lithium Transition-Metal Oxide/Activated Carbon Composite Positive Electrodes
}

\author{
Kyoungho Kim, ${ }^{*}$ Min-Soo Kim, ${ }^{\dagger}$ and Taewhan Yeu ${ }^{\star}$ \\ LG Innotek.1271, Sa 1-dong, Sangrok-gu, Ansan-si, Gyeonggi-do 426-791, Korea. ${ }^{*}$ E-mail: khkimecl@empal.com \\ ${ }^{\dagger}$ Department of Chemical and Biomolecular Engineering, Korea Advanced Institute of Science and Technology (KAIST), \\ 335 Gwahangno (373-1 Guseong-dong), Yuseong-gu, Daejeon 305-701, Korea \\ ${ }^{\ddagger}$ School of Chemical Engineering and Materials Science, Chung-Ang University, Seoul 156-756, Korea \\ Received May 14, 2010, Accepted September 6, 2010
}

\begin{abstract}
In order to increase the specific capacitance and energy density of supercapacitors, non-aqueous supercapacitors were prepared using lithium transition-metal oxides and activated carbons as active materials. The electrochemical properties were analyzed in terms of the content of lithium transition-metal oxides. The results of cyclic voltammetry and ACimpedance analyses showed that the pseudocapacitance may stem from the synergistic contributions of capacitive and faradic effects; the former is due to the electric double layer which is prepared in the interface of activated carbon and organic electrolyte, and the latter is due to the intercalation of lithium $\left(\mathrm{Li}^{+}\right)$ions. The specific capacitance and energy density of a supercapacitor improved as the lithium transition-metal oxides content increased, showing $60 \%$ increase compared to those of supercapacitor using a pure activated carbon positive electrode.
\end{abstract}

Key Words: Lithium transition-metal oxide, Supercapacitor, Intercalation, Non-aqueous electrolyte, Energy density

\section{Introduction}

Interest in supercapacitors as a main or a sub-power source for various applications requiring high power density such as electric vehicles, UPS systems and windmills has increased. ${ }^{1-2}$ The use of supercapacitors in the applications described above is thus far insufficient because the energy density is only one tenth of that in a secondary battery.

Therefore, many researchers have investigated methods to improve the working voltage, specific capacitance, and energy density of supercapacitors. In an effort to improve the working voltage of supercapacitors, researchers have attempted to prevent or reduce electrochemical reactions between the electrodes and electrolyte interfaces; i.e., they have researched methods of removing functional groups of activated carbons.

A considerable amount of research has been devoted in this area to increasing the specific capacitance and energy density. Different studies have attempted to enlarge the effective surface area of activated carbon or have prepared composite electrodes via an addition of transition metal oxides or conducting polymers. ${ }^{2-4}$ Obtaining large surface areas through ordinary methods increased the surface areas of micro-pores by only $20 \AA$ or less. However, on such surfaces, it was difficult for the electrolyte to penetrate into the micro-pores. Thus, these micro-pores did not successfully improve the specific capacitance or energy density. ${ }^{5}$

Recently, to solve those problems, new approaches, collectively known as composite activation methods, have been attempted. These methods involve chemical activation and electrochemical activation. Chemical activation is carried out with potassium hydroxide or vapor in which electrochemically injected ions of a particular size are subsequently used to obtain more meso-pores $(20 \sim 500 \AA)$ and fewer micro-pores. ${ }^{6}$

Another approach to increase the specific capacitance and energy density involves the use of the transition metal oxides such as ruthenium oxide $\left(\mathrm{RuO}_{2}\right)$, cobalt oxide $\left(\mathrm{Co}_{3} \mathrm{O}_{4}\right)$, and nickel oxide $\left(\mathrm{NiO}_{2}\right)$, which are electrochemically prepared or are created in a sol-gel process. These transition metal oxides are combined with activated carbons and are used as active materials. However, most of transition metal oxides are restricted to aqueous electrolytes; as a result, their rated voltage is only $1.2 \mathrm{~V}$ or less. Furthermore, these materials are expensive and require highly complex manufacturing processes. ${ }^{7-9}$

Lithium transition-metal oxides, such as lithium cobalt oxide $\left(\mathrm{LiCoO}_{2}\right)$ and lithium manganese oxide $\left(\mathrm{LiMn}_{2} \mathrm{O}_{4}\right)$, have a high capacity in theory, and activated carbons have large surface areas. Hence, the purpose of the present paper is to examine the electrochemical properties of lithium transition-metal oxide/activated carbon composites as active electrodes. In addition, this paper aims to develop supercapacitors that use non-aqueous electrolyte to obtain a working voltage higher than $1.2 \mathrm{~V}$. Lithium transition-metal oxide/activated carbon composites as positive electrodes were prepared with various ratios. Their physical and electrical properties were analyzed using particle size analyzer (PSA), scanning electron microscope (SEM) and surface conductivity measurements.

Non-aqueous supercapacitors were made using activated carbons as negative electrodes and (0.5 $\mathrm{M} \mathrm{LiBF}_{4}+0.5 \mathrm{M} \mathrm{Et}_{4}-$ $\mathrm{NBF}_{4} / \mathrm{ACN}$ ) as a non-aqueous electrolyte. The effects of the composition of a lithium transition-metal oxide/activated carbon composite on the electrochemical properties and the cycle properties of the supercapacitor were examined using ACimpedance, cyclic voltammetry and charge-discharge tests. 


\section{Experimental}

Mixtures of active materials, electric conductive materials and binding materials were prepared with fixed ratios of 75:15:10. Carbon black was used as the electric conductive material. Styrenebutadiene rubber, polytetrafluoroethylene, carboxymethylcellulose, and polyvinylpyrrolidone were used as water-soluble binding materials. The activated carbons were used as negative active materials. Lithium transition-metal oxides $\left(\mathrm{LiCoO}_{2}\right.$ and $\left.\mathrm{LiMn}_{2} \mathrm{O}_{4}\right)$ and the activated carbons were used as composite positive active materials. Lithium transition-metal oxide $\left(\mathrm{LiCoO}_{2}\right.$ and $\left.\mathrm{LiMn}_{2} \mathrm{O}_{4}\right)$, was purchased from Aldrich.

The negative and positive active materials were mixed at various ratios using distilled water as a solvent in all cases. The slurries were prepared by agitating the mixtures using a ball-mill method at a speed of $200 \mathrm{rpm}$ for 6 hours. The mixing was done at room temperature.

The well-mixed slurries were evenly coated on both sides of etched-aluminum foil of a thickness of $20 \mu \mathrm{M}$ using a Dr Blade method. The supercapacitors were prepared as follows: The coated electrodes were cut to $2 \times 5 \mathrm{~cm}$ in size and compressed at a pressure of $0.7 \sim 0.8 \mathrm{ton} / \mathrm{cm}^{2}$ at $120^{\circ} \mathrm{C}$. The cylinder-shaped elements were prepared by stitching the terminals and winding them in the presence of separation films. The manufactured cylinder-shaped elements were dried at $120^{\circ} \mathrm{C}$ for 48 hours under vacuum conditions of $30 \mathrm{mbar}$ or less. They were then sufficiently impregnated in the $0.5 \mathrm{M} \mathrm{LiBF}_{4}+0.5 \mathrm{M}$ $\mathrm{Et}_{4} \mathrm{NBF}_{4} / \mathrm{ACN}$ composite electrolyte in a glove box filled with nitrogen gas. Finally, the supercapacitors were sealed after rubber caps were inserted. Figure 1 shows the manufacturing processes of the supercapacitors.

The distribution of the particle sizes before and after the ballmilling process was determined using a PSA analysis. A SEM analysis, (500 in magnification), was conducted to observe the coating uniformity and measure the thickness of the coated active materials.

Surface conductivity measurements were carried out using four-probe method for the lithium transition-metal oxide/activated carbon composite positive electrode with and without

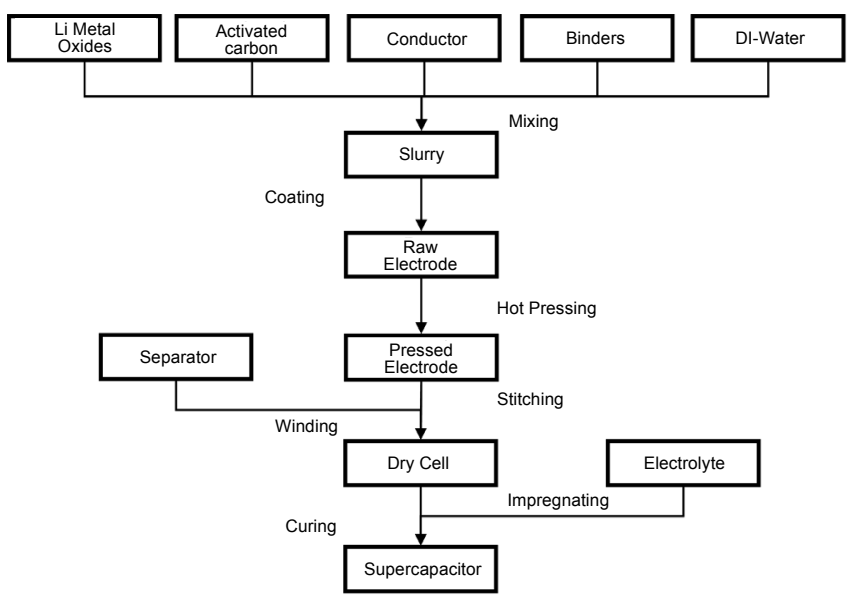

Figure 1. The preparation process of non-aqueous supercapacitors with composite positive electrodes. a conductive material. To verify intercalation of the lithium ions from the positive to the negative electrode, BET, Fourier transform infrared spectroscopy (FT-IR) and X-ray photoelectron spectroscopy (XPS) analyses were conducted.

An AC-impedance analysis was performed using an electrochemical impedance analyzer at a voltage of $\pm 1 \mathrm{mV}$ and a frequency range of $0.01 \sim 100,000 \mathrm{~Hz}$.

To check reversibility of the supercapacitors, cyclic voltammetry measurements were performed using a potentiostat/ galvanostat at a scan rate of $5 \mathrm{mV} / \mathrm{s}$ and an electric potential range of $1.0 \sim 2.3 \mathrm{~V}$. The specific capacitance and energy density of the supercapacitors were also measured using a cycler after the supercapacitors were discharged at a constant current of $1.0 \mathrm{~mA}$ and the reliability of the supercapacitors was determined in a charge/discharge experiment with 1000 trials at a speed of $10 \mathrm{C}$.

\section{Results and Discussion}

Figure 2 shows the particle size distributions of the lithium transition-metal oxides $\left(\mathrm{LiCoO}_{2}\right.$ and $\left.\mathrm{LiMn}_{2} \mathrm{O}_{4}\right)$, activated carbon, the conductive materials and the mixtures prepared using the ball-mill method. The average particle sizes of lithium

(a)

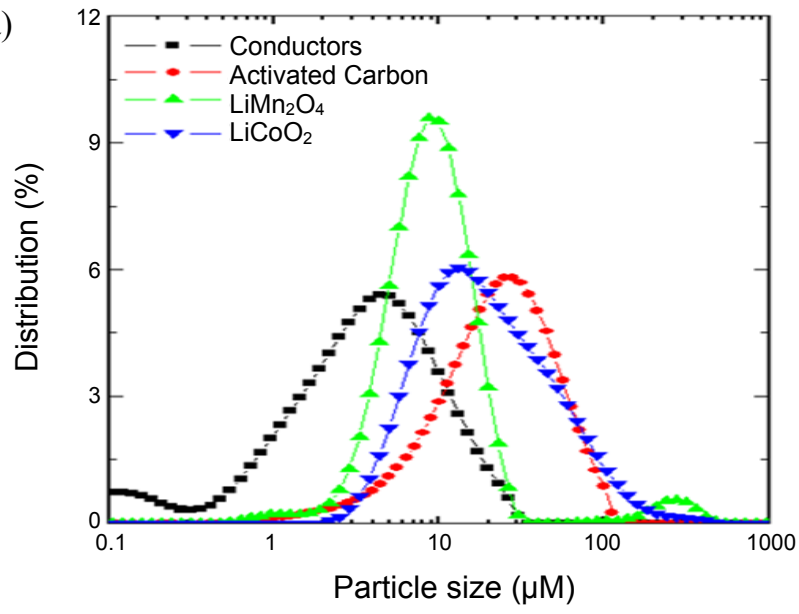

(b)

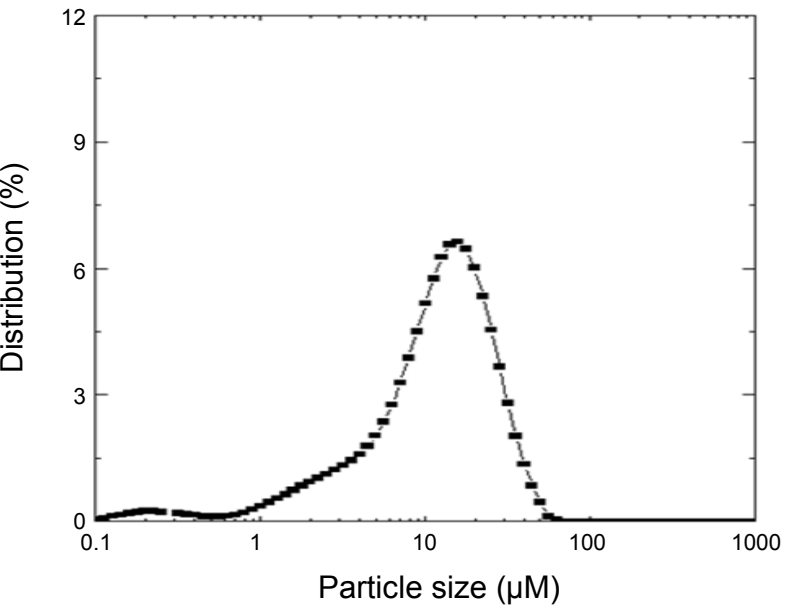

Figure 2. Particle size distribution of Lithium transition-metal oxide, activated carbon and conductor (a) before and (b) after ball-milling. 

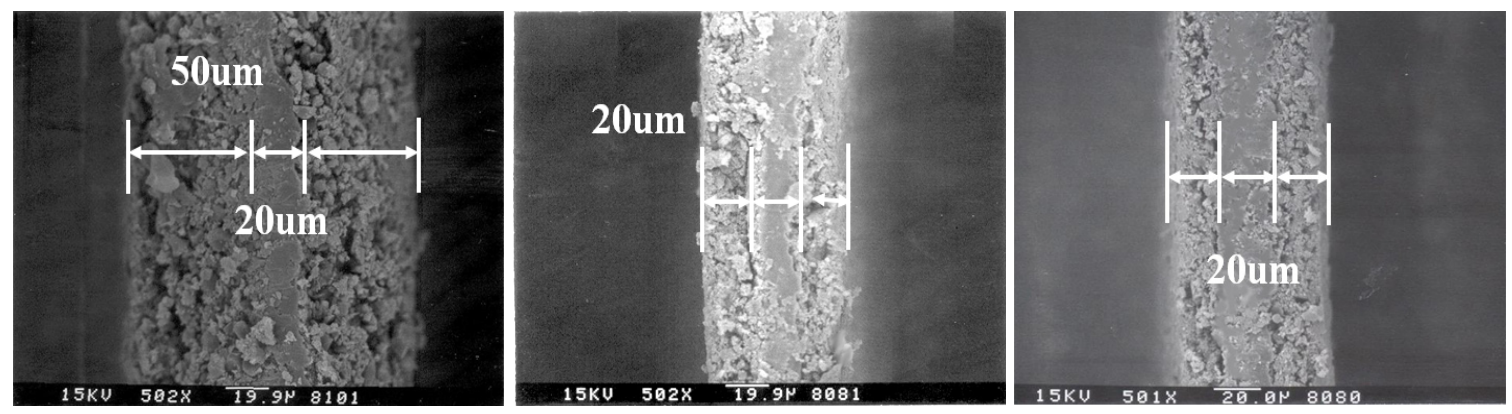

Figure 3. Cross sectional SEM micrograph of composite positive electrodes and activated carbon negative electrodes (500 magnitude ratio).

(a)

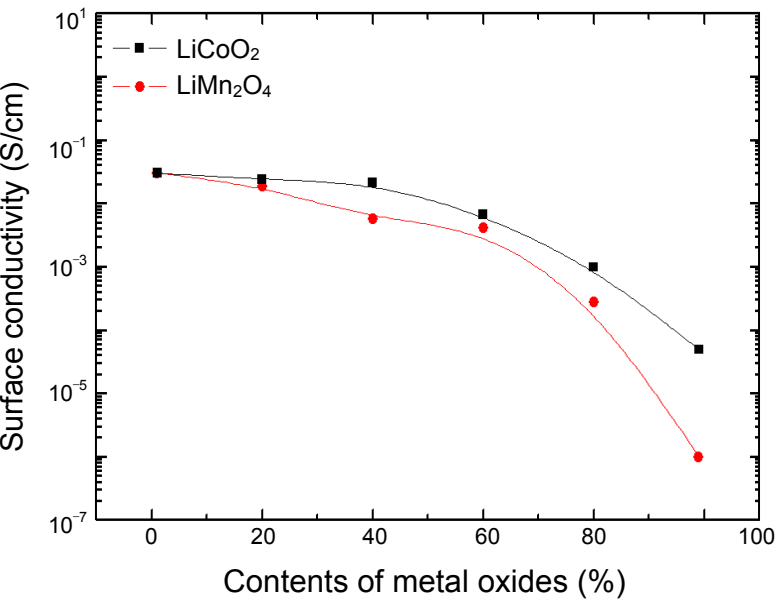

(b)

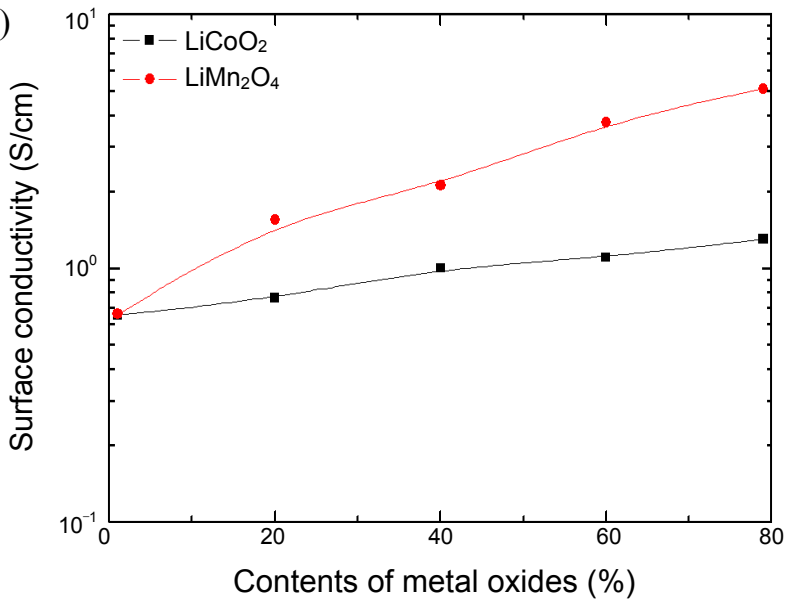

Figure 4. Surface conductivities of various composite positive electrodes (a) without and (b) with conductors

transition-metal oxide $\left(\mathrm{LiCoO}_{2}\right.$ and $\left.\mathrm{LiMn}_{2} \mathrm{O}_{4}\right)$, activated carbons, and the conductive materials were 12,30 and $5 \mu \mathrm{M}$, respectively. After prepared the particle size of lithium transitionmetal oxide by ball-mill method, $\mathrm{LiCoO}_{2}$ and $\mathrm{LiMn}_{2} \mathrm{O}_{4}$ had the same particle size distribution. However, the average particle size of the mixture was approximately $10 \mu \mathrm{M}$ after mixing the components using the ball-mill method.

Figure 3 shows SEM micrographs of the cross-sectional areas of lithium transition-metal oxide /activated carbon composite positive and activated carbon negative electrodes. As shown in the cross-sectional images, the active materials of the lithium transition-metal oxides/activated carbon composite positive and activated carbon negative electrodes were evenly coated at a thickness of $20 \pm 2 \mu \mathrm{M}$ and $50 \pm 2 \mu \mathrm{M}$, respectively, on both sides of the $20 \mu \mathrm{M}$-etched aluminum foil.

Figure 4 shows the effect of the presence of conductive material on the surface conductivities of lithium transition-metal oxide/activated carbon composite positive electrodes measured using four-probe method. The surface conductivities of the electrodes, which were prepared using active materials and binding materials without conductive material, decreased as the amount of lithium transition-metal oxides increased. In contrast, the surface conductivities of the electrodes increased with an increase in the content of lithium transition-metal oxides when a conductive material was added.

In principle, the surface conductivities decrease as the content of lithium transition-metal oxide in lithium transition-metal oxide/activated carbon composite electrodes increases, as the activated carbons have a surface conductivity of $10^{0} \sim 10^{-1}$ $\mathrm{S} / \mathrm{cm}$ while the lithium transition-metal oxides have a surface conductivity of $10^{-4} \sim 10^{-6} \mathrm{~S} / \mathrm{cm}$ which is close to that of a nonconducting substance. ${ }^{10-11}$ However, when a conductive material is added to the lithium transition-metal oxide/activated carbon composite electrodes, the formation of a matrix structure between the particles of the conductive material and lithium transition-metal oxide appears to be feasible given that the particle sizes of the conductive material and the lithium transitionmetal oxide were much smaller than that of the activated carbon. Therefore, as the contents of lithium transition-metal oxide increase, the ratio of activated carbon decrease in the lithium transition-metal oxide/activated carbon composite electrodes and the conductive matrix will be denser. In other words, although the contents of non-conductive materials such as the lithium transition-metal oxides increase, the matrix may have a structure covering the lithium transition-metal oxides with the conductive materials.

As a result, electricity can pass through the matrix structure that formed within the electrodes. The formation of the matrix structure is likely responsible for the apparent increase in the surface conductivity as the content of lithium transition-metal oxide increases.

Figure 5 (a) shows the BET analysis results of the activated carbon negative electrodes, before and after the charge/discharge test. The activated carbon negative electrodes, before the 
(a)

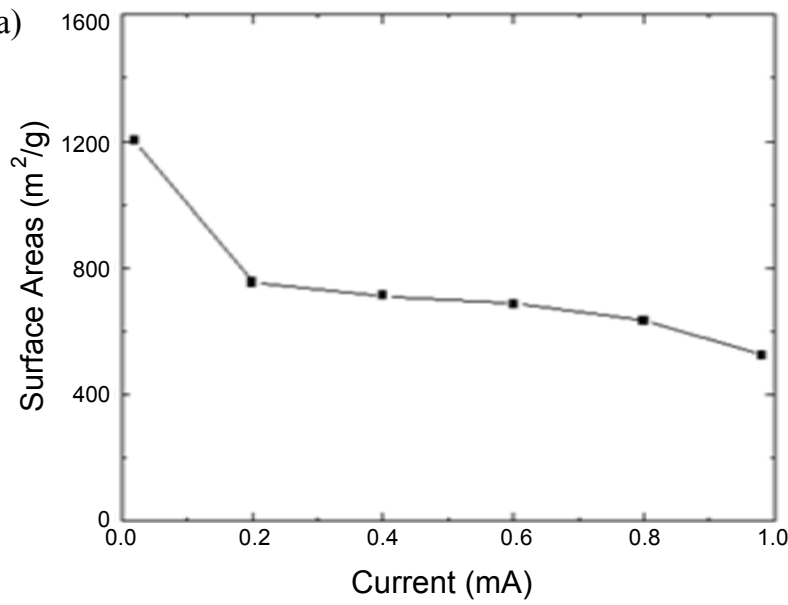

(b)

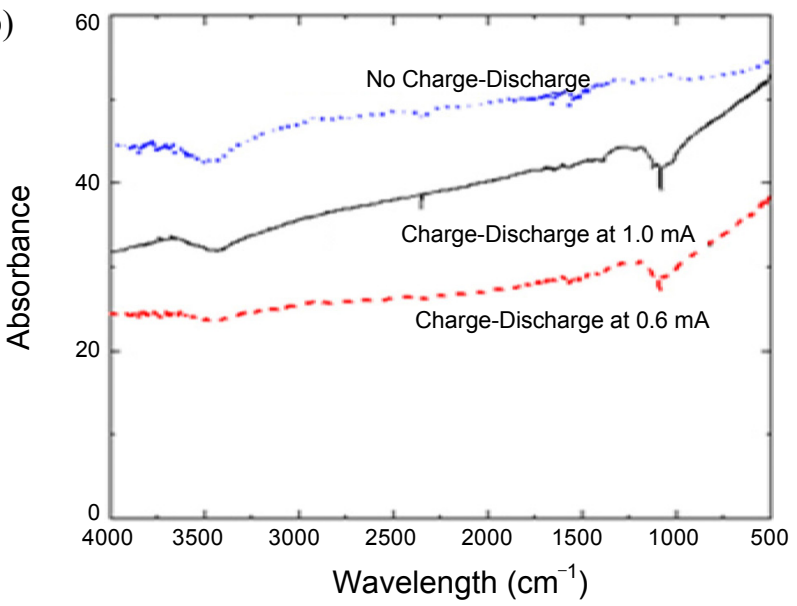

(c)

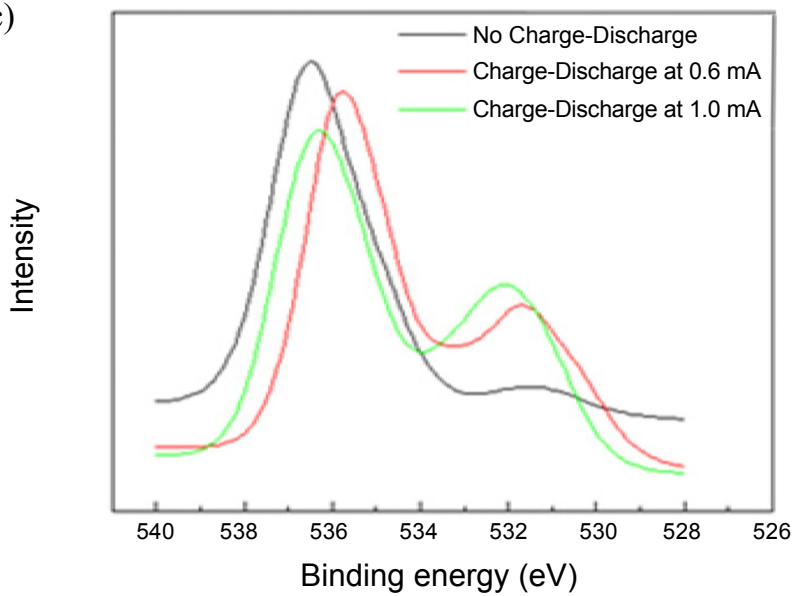

Figure 5. Analysis of activated carbon negative electrodes (a) BET, (b) FT-IR and (c) XPS.

charge/discharge test, had large surface areas of approximately $1200 \mathrm{~m}^{2} / \mathrm{g}$. However, after the charge/discharge test, the surface areas of the negative electrodes decreased to a range of $600 \sim 800$ $\mathrm{m}^{2} / \mathrm{g}$. That results from the pores of the activated carbons that were closed or destroyed and that was proposed to be a possibility of SEI (Solid Electrolyte Interface) layer. When lithium ions, intercalated for initially charging lithium ion battery, are injected in graphite as negative electrode, they may be combin- ed with the electrolyte which is separated from the interface of negative electrode. That is called as SEI layer, of which the components are known as ROLi or $\mathrm{ROCO}_{2} \mathrm{Li}^{15-17}$

Figure 5 (b) shows the FT-IR analysis results of the activated carbon negative electrodes before and after the charge/discharge test. Before and after the charge/discharge test, the FT-IR peaks were similar; both cases were in the $500 \sim 4000 \mathrm{~cm}^{-1}$ wavelength range. However, a different peak such as ROLi or $\mathrm{ROCO}_{2} \mathrm{Li}$ appeared in $1100 \sim 1350 \mathrm{~cm}^{-1}$ wavelength range. ${ }^{18-19}$

Figure 5 (c) shows the XPS analysis results of the activated carbons negative electrodes before and after the charge/discharge test. Different peaks appeared in the $531 \sim 532 \mathrm{eV}$ range before and after the charge/discharge test. In many articles, these peaks are predicted by ROLi or $\mathrm{ROCO}_{2} \mathrm{Li}^{12-14}$ They stem from a reaction between functional groups (e.g. $-\mathrm{COOH},-\mathrm{CO},-\mathrm{H},=$ $\mathrm{O}$ etc.) on the activated carbons and intercalated lithium ions

Figure 6 shows Nyquist plots of supercapacitors with various lithium transition-metal oxide/activated carbon composite positive electrodes obtained from the analysis of the AC-impedance. For general electrochemical devices, in high frequency $(1,000 \sim$ $100,000 \mathrm{~Hz}$ ), a polarization effect is observed and semi-circles are shown by polarization. In low frequency $(0.01 \sim 10 \mathrm{~Hz})$, a mass transfer effect is observed and the lines, which are parallel to imaginary axis or lower than 90-degree angle to real axis in Nyquist plot, are shown by mass transfer. In middle frequency $(10 \sim 1,000 \mathrm{~Hz})$, polarization effect or mass transfer effect or superposition effect by both them are observed. In the case of the superposition, the behavior of Warburg impedance or incomplete semicircle is revealed.

The supercapacitor using $0 \mathrm{wt} \%$ lithium transition-metal oxide/C composite electrode did not show any semicircles by the polarization in high frequency but only the vertical lines by mass transfer in low frequency, which is typical for conventional capacitor. It is considered that because of the formation of electrical double layer by non-faradic reaction, any polarization is not occurred. The supercapacitor using 20, 40, 60 and $80 \mathrm{wt} \%$ lithium transition-metal oxide/C composite electrode showed semicircles by polarization in high frequency and vertical lines by mass transfer in low frequency respectively.

However, in middle frequency $(10 \sim 1,000 \mathrm{~Hz})$, the behaviors of the supercapacitor were unlike the supercapacitor using 0 wt \% lithium transition-metal oxide/C composite electrode as shown Figure 6. The supercapacitor using $20 \mathrm{wt} \%$ lithium transition-metal oxide/C composite electrode showed stronger behavior by polarization effect than that by mss transfer effect without any special behavior. The supercapacitor using 40 and $60 \mathrm{wt} \%$ lithium transition-metal oxide/C composite electrode showed smaller semicircles than that of the supercapacitor using $20 \mathrm{wt} \%$ lithium transition-metal oxide/C composite electrode and vertical lines which are more parallel to imaginary axis. It is considered that the behaviors result from superposition effect by both polarization and mass transfer. The supercapacitor using $80 \mathrm{wt} \%$ lithium transition-metal oxide/C composite electrodes showed the semicircles depressed to real-axis and it is considered that the behaviors result from the superposition as mentioned above. Especially, the behaviors are known due to the intercalation of $\mathrm{Li}^{+}$ion.

In short, within a frequency range of $0.01 \sim 1,000 \mathrm{~Hz}$, the 
(a)

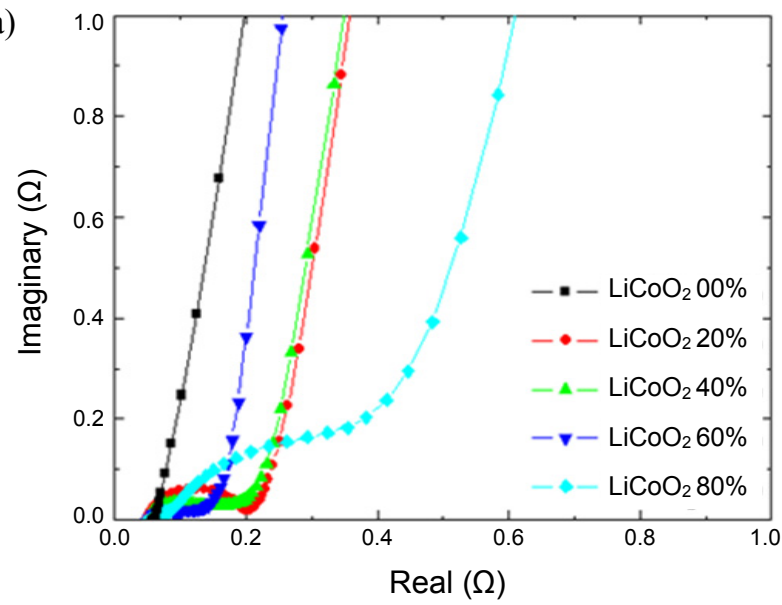

(b)

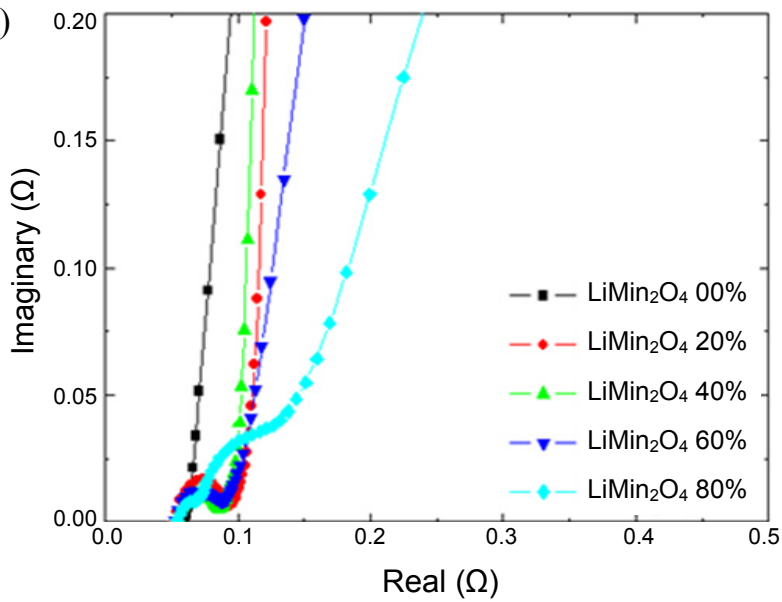

Figure 6. Nyquist plots of supercapacitors with various composite positive electrodes (a) $\mathrm{LiCoO}_{2}$ and (b) $\mathrm{LiMn}_{2} \mathrm{O}_{4}$.

(a)

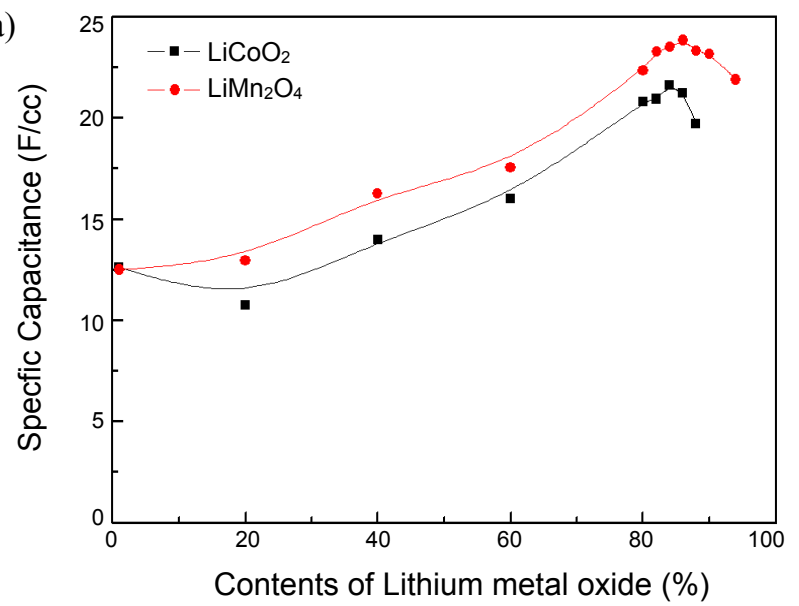

(a)

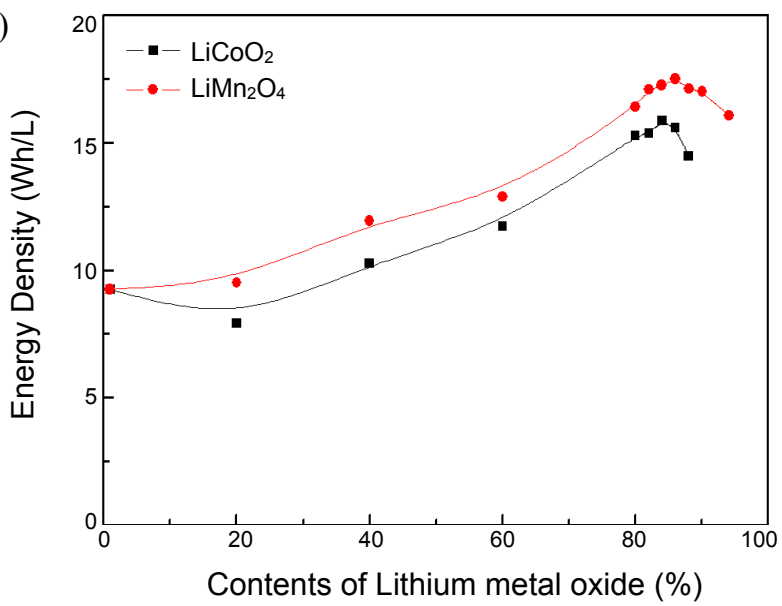

Figure 7. Specific capacitances (a) and energy densities (b) of supercapacitor with various composite positive electrodes.

specific reactions have occurred between the electrode interface of the supercapacitor. The ohmic resistance values of the supercapacitors were approximately $50 \mathrm{~m} \Omega$, and the value decreased slightly as the lithium transition-metal oxide content increased. These results are consistent with those obtained from the surface conductivity measurements, as shown in Figure 4. The Nyquist plot for the pure activated carbon positive electrodes revealed a vertical curve, which is typical for conventional capacitor. The polarization resistance increased as the content of the lithium transition-metal oxide increased; these results stemmed from the intercalation and diffusion of $\mathrm{Li}^{+}$ions. In particular, the reactions of the negative and composite positive electrodes were delineated into two clear semicircles as the content of the lithium transition-metal oxides exceed $80 \%$.

Figure 7 shows the specific capacitances and energy density values of supercapacitors with various lithium transition-metal oxide/activated carbon composite positive electrodes as measured by a cycler. The resulting ratios of the increase in the specific capacitance and energy density appear to be due to the manifestation of pseudocapacitance as the content of the lithium transition-metal oxide increases. The highest values, i.e., a specific capacitance of $23.83 \mathrm{~F} / \mathrm{cc}$ and an energy density of $17.51 \mathrm{Wh} / \mathrm{L}$, were obtained when the ratio of $\mathrm{LiMn}_{2} \mathrm{O}_{4} / \mathrm{C}$ was $0.86 / 0.14$.

The effect of the content of lithium transition-metal oxides in lithium transition-metal oxide/activated carbon composite positive electrodes on the cyclic voltammetry of the supercapacitors is shown in Figure 8. For all compositions of composite positives, the supercapacitors showed excellent reversibility and typical capacitor operations. The charge/discharge current densities of the supercapacitors increased as the lithium transition-metal oxide concentration increased; these results most likely stemmed from the occurrence of pseudocapacitance which resulted from the synergistic contributions of capacitive and faradic effects; the former effect was due to the electric double layer which was increasingly generated at the interface of the positives and electrolyte with the increasing lithium transition-metal oxide content, and the latter effect stemmed from the intercalation of $\mathrm{Li}^{+}$ions. These results are in good agreement with those of AC-impedance analysis shown in Figure 6.

The reliability of the supercapacitors created using the lithium 
(a)

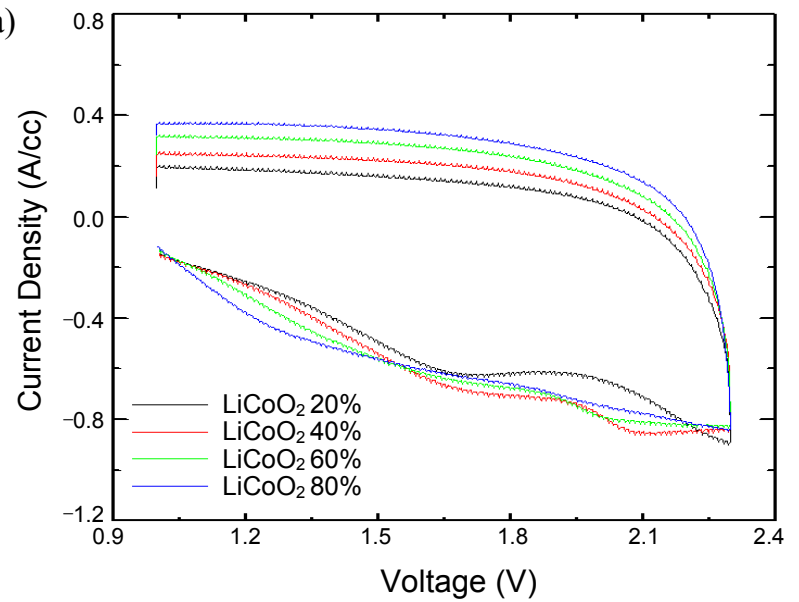

(b)

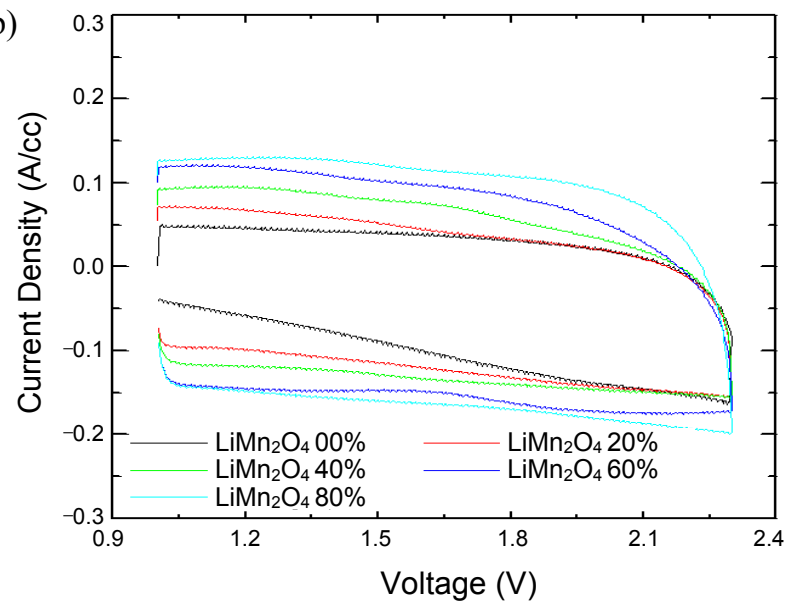

Figure 8. Cyclic voltammograms of supercapacitors with various composite positive electrodes at $5 \mathrm{mV} / \mathrm{sec}(\mathrm{a}) \mathrm{LiCoO}_{2}$ and $(\mathrm{b}) \mathrm{LiMn}_{2} \mathrm{O}_{4}$.

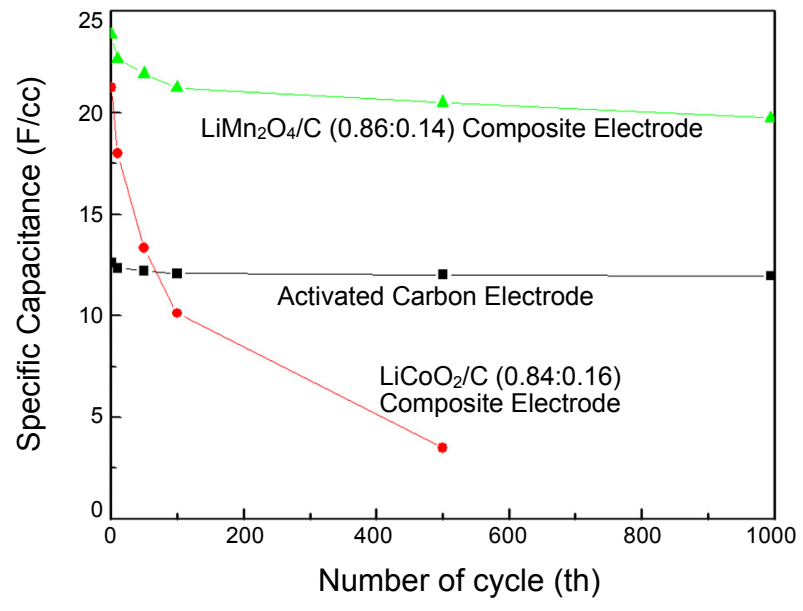

Figure 9. Specific capacitances of supercapacitors at $10 \mathrm{C}$ rates charge/ discharge.

transition-metal oxide/activated carbon composite positive electrodes, whose ratios were 0.86/0.14 $\left(\mathrm{LiMn}_{2} \mathrm{O}_{4} / \mathrm{C}\right)$ and $0.84 / 0.16\left(\mathrm{LiCoO}_{2} / \mathrm{C}\right)$, was determined by charging/discharging measurements using cycler at a speed of $10 \mathrm{C}$. These results are shown in Figure 9. The greatest reduction in specific capacitance and in the energy density of the supercapacitors occurred at the initial stage of the charge-discharge test, and the use of the $\mathrm{LiMn}_{2} \mathrm{O}_{4} / \mathrm{C}$ composite positive electrodes induced a somewhat higher reduction of the specific capacitance and energy density compared to an electrode consisting of pure activated carbon; however, the supercapacitor with the $\mathrm{LiMn}_{2} \mathrm{O}_{4} / \mathrm{C}$ composite positive electrode showed a significant improvement, i.e., greater than $60 \%$, in terms of its specific capacitance and energy density compared with the supercapacitor of pure activated carbon electrode even after 1000 charge-discharge tests. However, supercapacitors with the $\mathrm{LiCoO}_{2} / \mathrm{C}$ composite positive electrode showed a significant decrease, i.e. in excess of $90 \%$, in terms of the specific capacitance and energy density compared to those created with a pure activated carbon electrode, even after 500 charge-discharge tests.

The difference of the specific capacitance for the cycle tests with lithium transition-metal oxides results from the structural difference of the lithium transition-metal oxide. $\mathrm{LiCoO}_{2}$ have a layered structure but the layered structure is spoiled by repetition of intercalation and deintercalation, whereas $\mathrm{LiMn}_{2} \mathrm{O}_{4}$ have a spinal structure and the structure is scarcely damaged for the cycle tests. Therefore the supercapacitor using $\mathrm{LiMn}_{2} \mathrm{O}_{4}$ can maintain the higher specific capacitance than that of $\mathrm{LiCoO}_{2}$ because of the structural stability.

\section{Conclusions}

The electrochemical properties of supercapacitors using a lithium transition-metal oxide/activated carbon composite as a positive electrode were investigated. Detailed AC impedance and cyclic voltammetry investigations revealed that the manifestation of pseudocapacitance may stem from the intercalation of $\mathrm{Li}^{+}$ions. The optimum values of the specific capacitance and energy density, which are $23.8 \mathrm{~F} / \mathrm{cc}$ and $17.5 \mathrm{Wh} / \mathrm{L}$, respectively, were obtained when a $\mathrm{LiMn}_{2} \mathrm{O}_{4} / \mathrm{C}$ composite with a ratio of $0.86 / 0.14$ was used as a positive electrode; these values are the initial values and are two times higher than those obtained from supercapacitors with a pure activated carbon electrode. In addition, even after 1000 trials of a charge-discharge test, the values of the specific capacitance and energy density of the supercapacitor with the composite electrode were $60 \%$ higher than those of the supercapacitor with the pure carbon electrode.

\section{References}

1. Conway, B. E. Electrochemical Supercapacitors, Scientific Fundamentals and Technological Application; Kluwer Academic/Plenum Publishers: New York, 1999.

2. Miller, J. M.; Dunn, B.; Tran, T. D.; Pekala, R. W. J. Electrochem. Soc. 1997, 144, L309.

3. Sato, Y.; Yomogida, K.; Nanaumi, T.; Kobayakawa, K.; Ohsawa, Y.; Kawai, M. Electrochem. Solid State Lett. 2000, 3, 113.

4. Kim, K. M.; Hur, J. W.; Jung, S. I.; Kang, A. S. Electrochim. Acta 2004, 50, 863.

5. Michael, M. S.; Parbaharn, S. R. S. J. Power Sources 2004, 136, 250.

6. Amatucci, G. G.; Badway, F.; Pasquier, A. D.; Zheng, T. J. Electrochem. Soc. 2001, 148, A930. 
7. Frackowiak, E.; Beguin, F. Carbon 2001, 39, 937.

8. Okamura, M.; Takeuchi, M. US20020012223 2002.

9. Ramani, M.; Haran, B. S.; White, R. E.; Popov, B. N. J. Electrochem. Soc. 2001, 148, A374.

10. Srinivasan, V.; Weidner, J. W. J. Electrochem. Soc. 1997, 144, L210.

11. Liu, K.; Anderson, M. A. J. Electrochem. Soc. 1996, 143, 124.

12. Du Pasquier, A.; Plitz, I.; Gural, J.; Badway, F.; Amatucci, G. G. J. Power Sources 2004, 136, 160.

13. Tukamoto, H.; West, A. R. J. Electrochem. Soc. 1997, 144, 3164.
14. Holbery, J. D.; Seddon, K. R. Clean Products and Processes 1999, $1,223$.

15. Aurbach, D.; Markovsky, B.; Weissman, I.; Levi, E.; Ein-Eli, Y. Electrochim. Acta 1999, 45, 67.

16. Araki, K.; Sato, N. J. Power Sources 2003, 124, 124.

17. Bar-Tow, D.; Peled, E.; Burstein, L. J. Electrochem. Soc. 1999, 146(3), 824.

18. Fischer, T.; Sethi, A.; Welton T.; Woolf, J. Tetrahedron Lett. 1999, 40,793 .

19. Weltion, T. Chem. Rev. 1999, 99, 2071. 